\title{
Mixed Convection Flow Adjacent to a Stretching Vertical Sheet in a Nanofluid
}

\author{
Nor Azizah Yacob, ${ }^{1}$ Anuar Ishak, ${ }^{2}$ Roslinda Nazar, ${ }^{2}$ and Ioan Pop ${ }^{3}$ \\ ${ }^{1}$ Faculty of Computer and Mathematical Sciences, Universiti Teknologi MARA Pahang, 26400 Bandar Tun Razak Jengka, \\ Pahang, Malaysia \\ ${ }^{2}$ School of Mathematical Sciences, Faculty of Science and Technology, Universiti Kebangsaan Malaysia, 43600 Bangi, \\ Selangor, Malaysia \\ ${ }^{3}$ Department of Mathematics, Babeş-Bolyai University, 400084 Cluj-Napoca, Romania
}

Correspondence should be addressed to Anuar Ishak; anuarishak@yahoo.com

Received 27 December 2012; Accepted 20 June 2013

Academic Editor: Subhas Abel

Copyright (C) 2013 Nor Azizah Yacob et al. This is an open access article distributed under the Creative Commons Attribution License, which permits unrestricted use, distribution, and reproduction in any medium, provided the original work is properly cited.

The characteristics of fluid flow and heat transfer over a stretching vertical sheet immersed in a nanofluid are investigated numerically in this paper. Three different types of nanoparticles, namely, copper $\mathrm{Cu}$, alumina $\mathrm{Al}_{2} \mathrm{O}_{3}$, and titania $\mathrm{TiO}_{2}$, are considered, using water as the base fluid. It is found that nanofluid with titania nanoparticles has better enhancement on the heat transfer rate compared to copper and alumina nanoparticles. For a particular nanoparticle, increasing the nanoparticle fraction is to reduce the skin friction coefficient and the heat transfer rate at the surface.

\section{Introduction}

Nanofluids are defined as dilute suspensions of particles with at least one critical dimension smaller than around $100 \mathrm{~nm}$ and are also known as two-phase fluid [1]. Nanofluids are produced by dispersing nanometer-scale solid particles into base liquids with low thermal conductivity such as water, ethylene glycol (EG), and oils [2]. Nanofluids can be Newtonian or non-Newtonian fluids. The term "nanofluids" was first introduced by Choi [3]. There are mainly two techniques used to produce nanofluids which are the singlestep and the two-step methods (see Akoh et al. [4] and Eastman et al. [5]). Both of these methods have advantages and disadvantages as discussed by Wang and Mujumdar [2]. The materials with sizes of nanometers possess unique physical and chemical properties [6]. They can flow smoothly through microchannels without clogging them because they are small enough to behave similar to liquid molecules [7]. This fact has attracted many researchers such as Abu-Nada and Oztop [6], Tiwari and Das [8], El Bécaye Maïga et al. [9], Polidori et al. [10], Talebi et al. [11], Akbari et al. [12], and Shahi et al. [13] to investigate the heat transfer characteristics of nanofluids in cavities, and they found that the presence of the nanoparticles in the fluids increases appreciably the effective thermal conductivity of the fluid and consequently enhances the heat transfer characteristics. The recent book by Das et al. [14] and the more recent review paper by Kakaç and Pramuanjaroenkij [15] present an excellent collection of the work done on nanofluids.

Motivated by the above investigations, the present paper considers the problem of mixed convection boundary layer flow adjacent to a stretching vertical sheet immersed in a nanofluid, using the nanofluid model proposed by Tiwari and Das [8], which was also used by several authors (cf. Abu-Nada and Oztop [6], Talebi et al. [11], Abu-Nada [16], Ahmad et al. [17], Rohni et al. [18], Bachok et al. [19-23], Yacob et al. [24, 25], and Muthtamilselvan et al. [26]). As mentioned by El Bécaye Maïga et al. [9], the study of boundary layer flow is important because the reduction of the thermal boundary layer thickness due to the presence of particles and their random motion within the base fluid may have important contributions to such heat transfer improvement as well. It should be pointed out that there is only a very little work done on boundary layer flow of nanofluids, as can be seen in 
the recent papers by Nield and Kuznetsov [27] and Kuznetsov and Nield [28].

It is worth mentioning that nanofluids, with nanosized particles, appear to have a very high thermal conductivity and may be able to meet the rising demand as an efficient heat transfer agent. Scientists and engineers have started showing interest in the study of heat transfer characteristics of these nanofluids. However, a clear picture about the heat transfer through these nanofluids is yet to emerge. Taking into account the rising demands of modern technology, including chemical production, power stations, and microelectronics, there is a need to develop new types of fluids that will be more effective in terms of heat exchange performance [26].

\section{Problem Formulation}

Consider a steady mixed convection flow of a nanofluid adjacent to a stretching vertical sheet with a linear velocity $u_{w}(x)=a x$, where $a$ is a constant and $x$ is the coordinate measured along the stretching sheet in the vertical direction. The flow takes place at $y \geq 0$, where $y$ is the coordinate measured normal to the stretching sheet. It is assumed that the temperature at the stretching surface is $T_{w}(x)=T_{\infty}+b x$, where $b$ is a constant and $T_{\infty}$ is the constant temperature of the ambient fluid.

The basic equations of continuity, momentum, and energy for nanofluids can be obtained, written in Cartesian coordinates $x$ and $y$ as (see Oztop and Abu-Nada [29])

$$
\begin{gathered}
\frac{\partial u}{\partial x}+\frac{\partial v}{\partial y}=0 \\
u \frac{\partial u}{\partial x}+v \frac{\partial u}{\partial y}=-\frac{1}{\rho_{\mathrm{nf}}} \frac{\partial p}{\partial x}+\frac{\mu_{\mathrm{nf}}}{\rho_{\mathrm{nf}}}\left(\frac{\partial^{2} u}{\partial x^{2}}+\frac{\partial^{2} u}{\partial y^{2}}\right) \\
+\frac{\phi \rho_{s} \beta_{s}+(1-\phi) \rho_{f} \beta_{f}}{\rho_{\mathrm{nf}}}\left(T-T_{\infty}\right), \\
u \frac{\partial v}{\partial x}+v \frac{\partial v}{\partial y}=-\frac{1}{\rho_{\mathrm{nf}}} \frac{\partial p}{\partial y}+\frac{\mu_{\mathrm{nf}}}{\rho_{\mathrm{nf}}}\left(\frac{\partial^{2} v}{\partial x^{2}}+\frac{\partial^{2} v}{\partial y^{2}}\right) \\
u \frac{\partial T}{\partial x}+v \frac{\partial T}{\partial y}=\frac{\partial}{\partial x}\left(\alpha_{\mathrm{nf}} \frac{\partial T}{\partial x}\right)+\frac{\partial}{\partial y}\left(\alpha_{\mathrm{nf}} \frac{\partial T}{\partial y}\right)
\end{gathered}
$$

subject to the boundary conditions

$$
\begin{gathered}
u=u_{w}(x), \quad v=0, \quad T=T_{w}(x) \quad \text { at } y=0, \\
u \longrightarrow 0, \quad T \longrightarrow T_{\infty} \quad \text { as } y \longrightarrow \infty .
\end{gathered}
$$

Here, $u$ and $v$ are the velocity components along the $x$ and $y$ axes, respectively, $p$ is the fluid pressure, $\beta$ is the thermal expansion coefficient (with subscripts $f$ and $s$ standing for fluid and solid, respectively), $g$ is the gravitational acceleration, $\rho_{\mathrm{nf}}$ is the effective density of the nanofluid,, $\alpha_{\mathrm{nf}}$ is the effective thermal diffusivity of the nanofluid and $\mu_{\mathrm{nf}}$ is the dynamic viscosity of the nanofluid, which are given by (see Oztop and Abu-Nada [29])

$$
\begin{gathered}
\rho_{\mathrm{nf}}=(1-\phi) \rho_{f}+\phi \rho_{s}, \\
\alpha_{\mathrm{nf}}=\frac{k_{\mathrm{nf}}}{\left(\rho C_{p}\right)_{\mathrm{nf}}}, \\
\mu_{\mathrm{nf}}=\frac{\mu_{f}}{(1-\phi)^{2.5}},
\end{gathered}
$$

where $\phi$ is the nanoparticle fraction, $\rho_{f}$ is the density of the fluid, $\rho_{s}$ is the density of the solid, $\mu_{f}$ is the dynamic viscosity of the fluid, $k_{\mathrm{nf}}$ is the effective thermal conductivity of the nanofluid, and $\left(\rho C_{p}\right)_{\mathrm{nf}}$ is the heat capacity of the nanofluid, which are given by (see Oztop and Abu-Nada [29])

$$
\begin{gathered}
\frac{k_{\mathrm{nf}}}{k_{f}}=\frac{k_{s}+2 k_{f}-2 \phi\left(k_{f}-k_{s}\right)}{k_{s}+2 k_{f}+\phi\left(k_{f}-k_{s}\right)}, \\
\left(\rho C_{p}\right)_{\mathrm{nf}}=(1-\phi)\left(\rho C_{p}\right)_{f}+\phi\left(\rho C_{p}\right)_{s} .
\end{gathered}
$$

The use of the effective thermal conductivity of the nanofluid $k_{\mathrm{nf}}$ is approximated by the Maxwell-Garnetts model and is restricted to spherical nanoparticles, where it does not account for other shapes of nanoparticles. This model is found to be appropriate for studying heat transfer enhancement using nanofluids (Abu-Nada [16]).

We look for a similarity solution of (1)-(4) with the boundary conditions (5) by introducing the following transformation:

$$
\begin{aligned}
\psi(x, y)=\left[a v_{f}\right]^{1 / 2} x f(\eta), \quad \theta(\eta) & =\frac{T-T_{w}}{T_{w}-T_{\infty}}, \\
\eta & =\left[\frac{a}{v_{f}}\right]^{1 / 2} y,
\end{aligned}
$$

where the stream function $\psi$ is defined in the usual way as $u=\partial \psi / \partial y$ and $v=-\partial \psi / \partial x$. Equation (1) is automatically satisfied, and (2) and (4), respectively, reduce to the following nonlinear ordinary differential equations:

$$
\begin{gathered}
\frac{1}{(1-\phi)^{2.5}\left[(1-\phi)+\phi\left(\rho_{s} / \rho_{f}\right)\right]} f^{\prime \prime \prime}+f f^{\prime \prime}-f^{\prime 2} \\
+\lambda\left[\frac{\phi}{(1-\phi)\left(\rho_{f} / \rho_{s}\right)+\phi} \frac{\beta_{s}}{\beta_{f}}\right. \\
\left.+\frac{1-\phi}{\phi\left(\rho_{s} / \rho_{f}\right)+(1-\phi)}\right] \theta=0,
\end{gathered}
$$

$$
\frac{1}{\operatorname{Pr}} \frac{k_{\mathrm{nf}} / k_{f}}{(1-\phi)+\phi\left(\rho C_{p}\right) /\left(\rho C_{p}\right)_{f}} \theta^{\prime \prime}+f \theta^{\prime}-f^{\prime} \theta=0,
$$

subject to the boundary conditions

$$
\begin{aligned}
& f(0)=0, \quad f^{\prime}(0)=1, \quad \theta(0)=1, \\
& f^{\prime}(\eta) \longrightarrow 0, \quad \theta(\eta) \longrightarrow 0 \quad \text { as } \eta \longrightarrow \infty,
\end{aligned}
$$


TABLE 1: Surface temperature gradient $\theta^{\prime}(0)$ for $\lambda=0, \phi=0$, and $\phi=0.1$.

\begin{tabular}{|c|c|c|c|c|c|c|}
\hline \multirow{3}{*}{$\operatorname{Pr}$} & \multirow{3}{*}{ Grubka and Bobba [30] } & \multicolumn{2}{|c|}{$\phi=0$} & \multirow{2}{*}{\multicolumn{3}{|c|}{$\begin{array}{c}\phi=0.1 \\
\text { Present results }\end{array}$}} \\
\hline & & \multirow{2}{*}{ Ishak et al. [31] } & \multirow{2}{*}{ Present results } & & & \\
\hline & & & & $\mathrm{Cu}$ & $\mathrm{Al}_{2} \mathrm{O}_{3}$ & $\mathrm{TiO}_{2}$ \\
\hline 0.72 & -0.8086 & - & -0.8086 & -0.6146 & -0.6590 & -0.6724 \\
\hline 1 & -1.0000 & -1.0000 & -1.0000 & -0.7765 & -0.8228 & -0.8392 \\
\hline 3 & -1.9237 & -1.9237 & -1.9237 & -1.5703 & -1.6175 & -1.6479 \\
\hline 7 & - & -3.0722 & -3.0723 & -2.5593 & -2.6057 & -2.6535 \\
\hline 10 & -3.7207 & -3.7207 & -3.7207 & -3.1171 & -3.1634 & -3.2211 \\
\hline
\end{tabular}

TABLE 2: Thermophysical properties of fluid and nanoparticles.

\begin{tabular}{lcccc}
\hline $\begin{array}{l}\text { Physical } \\
\text { properties }\end{array}$ & $\begin{array}{c}\text { Fluid phase } \\
\text { (water) }\end{array}$ & $\mathrm{Cu}$ & $\mathrm{Al}_{2} \mathrm{O}_{3}$ & $\mathrm{TiO}_{2}$ \\
\hline$C_{p}(\mathrm{~J} / \mathrm{kg} \mathrm{K})$ & 4179 & 385 & 765 & 686.2 \\
$\rho\left(\mathrm{KG} / \mathrm{m}^{3}\right)$ & 997.1 & 8933 & 3970 & 4250 \\
$k(\mathrm{~W} / \mathrm{m} \mathrm{K})$ & 0.613 & 400 & 40 & 8.9538 \\
$\alpha \times 10^{7}\left(\mathrm{~m}^{2} / \mathrm{s}\right)$ & 1.47 & 1163.1 & 131.7 & 30.7 \\
$\beta \times 10^{-5}(1 / \mathrm{K})$ & 21 & 1.67 & 0.85 & 0.9 \\
\hline
\end{tabular}

where primes denote differentiation with respect to $\eta, \operatorname{Pr}=$ $\nu_{f} / \alpha_{f}$ is the Prandtl number, and $\lambda$ is the buoyancy or mixed convection parameter, which is defined as

$$
\lambda=\frac{\mathrm{Gr}_{x}}{\operatorname{Re}_{x}^{2}}\left(=\frac{\beta_{f} g b}{a^{2}}\right),
$$

with $\mathrm{Gr}_{x}=g \beta_{f}\left(T_{w}-T_{\infty}\right) x^{3} / v_{f}^{2}$ being the local Grashof number and $\operatorname{Re}_{x}=u_{w}(x) x / v_{f}$ being the local Reynolds number.

The pressure $p$ can now be determined from (3) and is given by

$$
\frac{1}{\rho_{\mathrm{nf}}} p=-\frac{1}{2} v^{2}+\frac{\mu_{\mathrm{nf}}}{\rho_{\mathrm{nf}}} \frac{\partial v}{\partial y}+\text { constant }
$$

The physical quantities of interest are the skin friction coefficient $C_{f}$ and the Nusselt number $\mathrm{Nu}$, which are defined as

$$
C_{f}=\frac{\tau_{w}}{\rho_{f} u_{w}^{2}}, \quad \mathrm{Nu}=\frac{x q_{w}}{k_{f}\left(T_{w}-T_{\infty}\right)},
$$

where $\tau_{w}$ is the surface shear stress and $q_{w}$ is the surface heat flux, which are defined as

$$
\tau_{w}=\mu_{\mathrm{nf}}\left(\frac{\partial u}{\partial y}\right)_{y=0}, \quad q_{w}=-k_{\mathrm{nf}}\left(\frac{\partial T}{\partial y}\right)_{y=0} .
$$

Using variables in (8), we obtain

$$
\begin{gathered}
\operatorname{Re}_{x}^{1 / 2} C_{f}=\left(\frac{\mu_{\mathrm{nf}}}{\mu_{f}}\right) f^{\prime \prime}(0), \\
\operatorname{Re}_{x}^{-1 / 2} \mathrm{Nu}=-\left(\frac{k_{\mathrm{nf}}}{k_{f}}\right) \theta^{\prime}(0) .
\end{gathered}
$$

\section{Results and Discussion}

The nonlinear ordinary differential equations (9) subject to the boundary conditions (10) were solved numerically by means of an implicit finite-difference scheme known as the Keller-box method as described in the book by Cebeci and Bradshaw [32]. We have considered three different types of nanoparticles, namely, copper $(\mathrm{Cu})$, alumina $\left(\mathrm{Al}_{2} \mathrm{O}_{3}\right)$, and titania $\left(\mathrm{TiO}_{2}\right)$ with water as the base fluid. Following AbuNada [16], we considered the range of nanoparticle fraction as $0 \leq \phi \leq 0.2$. The Prandtl number of the base fluid (water) is kept constant at 7. It is worth mentioning that the present study reduces to the classical viscous fluid when $\phi=0$. Therefore, in order to validate the present numerical method used, we have compared our results with those obtained by Grubka and Bobba [30] and Ishak et al. [31] for different values of $\operatorname{Pr}$ when $\phi=0$ as shown in Table 1. The comparisons are found to be in a very good agreement. The thermophysical properties of fluid and nanoparticles are listed in Table 2.

Figure 1 shows the temperature distribution for the fluid with nanoparticle $\mathrm{Al}_{2} \mathrm{O}_{3}$ when $\lambda=1$. It can be seen that the thermal boundary layer thickness increases as the nanoparticle fraction $\phi$ is increased and consequently decreases the surface temperature gradient. This observation is consistent with the surface temperature gradient $-\theta^{\prime}(0)$ illustrated in Figure 2. The velocity distribution for $\mathrm{Cu}$ nanoparticles when $\lambda=1$ is presented in Figure 3. It can be seen that the velocity boundary layer thickness decreases with $\phi$, which in turn increases the velocity gradient at the surface.

Figure 4 displays the variation of the skin friction coefficient $f^{\prime \prime}(0)$ for different types of nanoparticles when $\phi=$ 0.1 , while the respective surface temperature gradient that represents the heat transfer rate at the surface is presented in Figure 5. We note that the values of $f^{\prime \prime}(0)$ obtained are quite similar for $\mathrm{TiO}_{2}$ and $\mathrm{Al}_{2} \mathrm{O}_{3}$. It is in agreement with the velocity gradient displayed in Figure 6. Further, from Table 2 and Figure 4, we observe that the nanoparticle with higher density (i.e., $\mathrm{Cu}$ ) has the lowest skin friction coefficient. The thermal boundary layer thickness as shown in Figure 7 decreases with a decrease in thermal conductivity $k$ (or low thermal diffusivity $\alpha_{\mathrm{nf}}$ ), which in turn gives rise to the Nusselt number $-\theta^{\prime}(0)$ as illustrated in Figure 5. Furthermore, the values of $f^{\prime \prime}(0)$ and $-\theta^{\prime}(0)$ increase as the buoyancy parameter $\lambda$ is increased. Note that the entire values of $-\theta^{\prime}(0)$ are always positive; that is, the heat is transferred from the hot sheet to the cold fluid. From Figures 1, 3, 6, and 


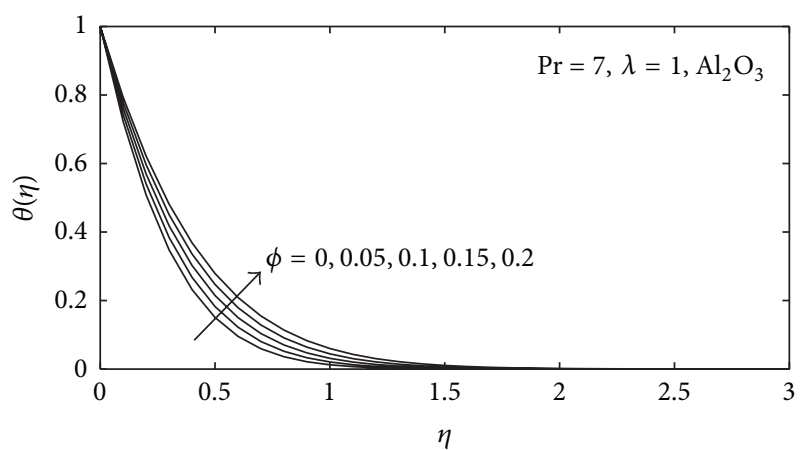

Figure 1: Temperature profiles $\theta(\eta)$ for different values of $\phi$ when $\operatorname{Pr}=7$ and $\lambda=1$ using $\mathrm{Al}_{2} \mathrm{O}_{3}$ nanoparticle.

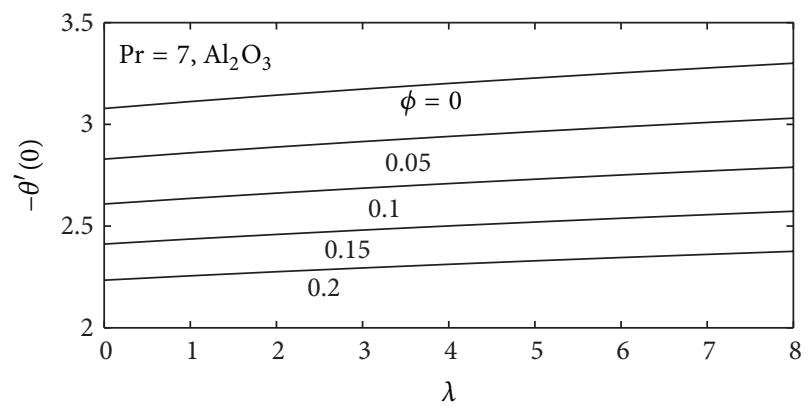

FIgURE 2: Variation of $-\theta^{\prime}(0)$ with $\lambda$ for different values of $\phi$ when $\mathrm{Pr}=7$ using $\mathrm{Al}_{2} \mathrm{O}_{3}$ nanoparticle.

7 , it is observed that the velocity and temperature profiles satisfy the far field boundary conditions (10) asymptotically, thus supporting the validity of the numerical results obtained.

The variations of $f^{\prime \prime}(0)$ and $-\theta^{\prime}(0)$ with $\phi$ for different types of nanoparticles when $\lambda=2$ are depicted in Figures 8 and 9 , respectively. It is clear that both of them decrease with increasing values of $\phi$. We notice that the effect of nanoparticle fraction on the skin friction coefficient is more pronounced for $\mathrm{Cu}$. A decrease in thermal conductivity is to enhance the heat transfer rate at the surface as shown in Figures 5 and 9. Conversely, the opposite behaviors are observed for the effect of nanoparticle fraction $\phi$. The thermal conductivity ratio with $\phi$ for different types of nanoparticles is presented in Figure 10. As expected, the thermal conductivity ratio increases with $\phi$, which follows from the relationship given by (7). However, it decreases with decreasing value of thermal conductivity of the nanoparticles.

\section{Conclusions}

The problem of steady two-dimensional laminar flow adjacent to a stretching vertical sheet immersed in a nanofluid was studied numerically. The governing partial differential equations were transformed into a system of nonlinear ordinary differential equations using a similarity transformation, before being solved numerically by the Keller-box method. It was found that nanofluid with $\mathrm{TiO}_{2}$ nanoparticles which has lower thermal conductivity has better heat transfer capability

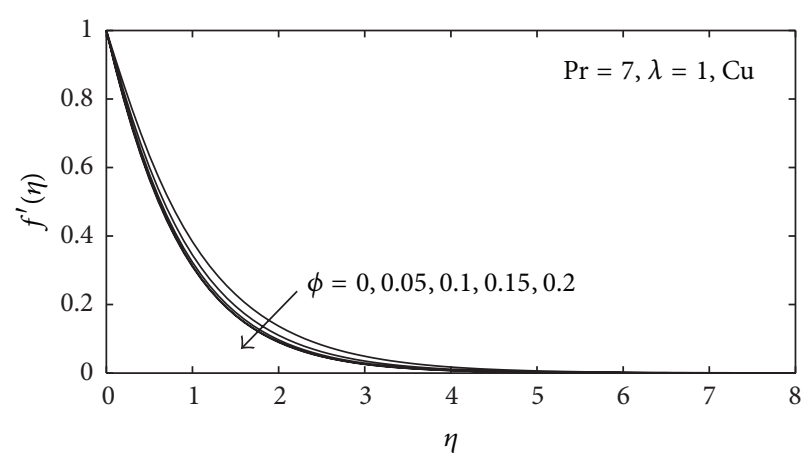

FIGURE 3: Velocity profiles $f^{\prime}(\eta)$ for different values of $\phi$ when $\operatorname{Pr}=7$ and $\lambda=1$ using $\mathrm{Cu}$ nanoparticle.

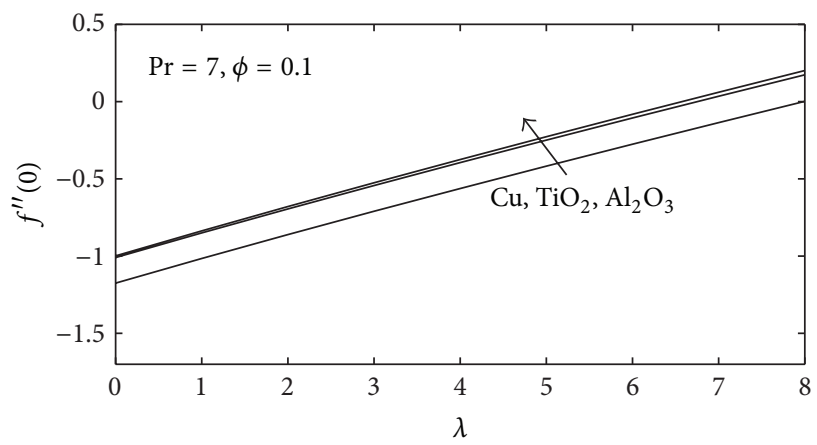

FIgURE 4: Variation of $f^{\prime \prime}(0)$ with $\lambda$ for different types of nanoparticles when $\operatorname{Pr}=7$ and $\phi=0.1$.

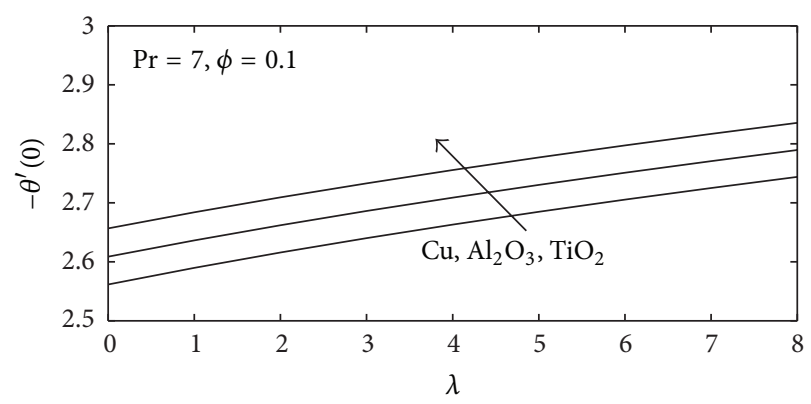

FIgURE 5: Variation of $-\theta^{\prime}(0)$ with $\lambda$ for different types of nanoparticles when $\operatorname{Pr}=7$ and $\phi=0.1$.

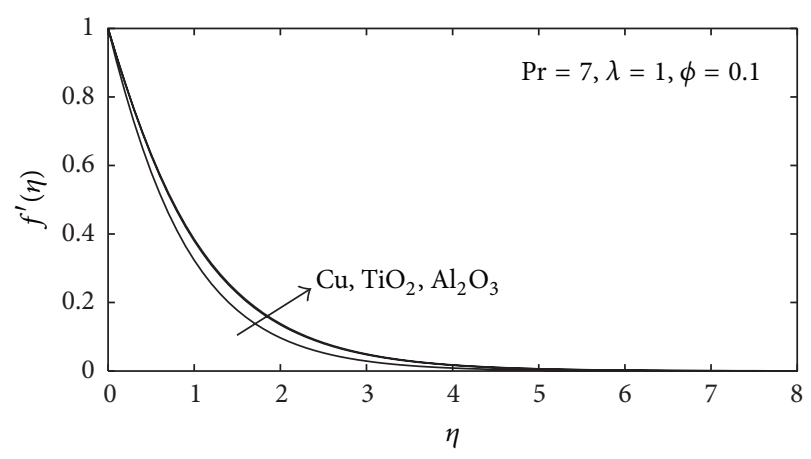

FIGURE 6: Velocity profiles $f^{\prime}(\eta)$ for different types of nanoparticles when $\operatorname{Pr}=7, \phi=0.1$, and $\lambda=1$. 


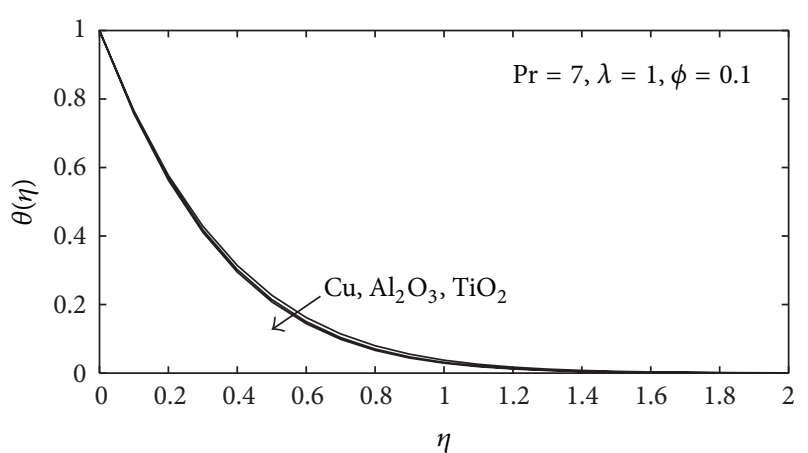

Figure 7: Temperature profiles $\theta(\eta)$ for different types of nanoparticles when $\operatorname{Pr}=7, \phi=0.1$, and $\lambda=1$.

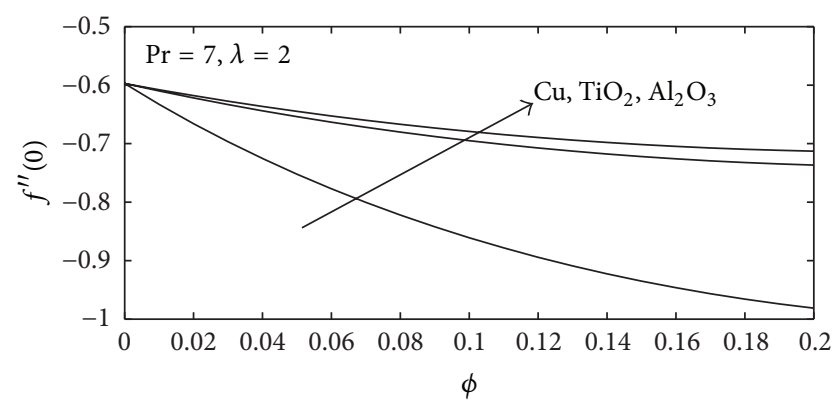

FIgURE 8: Variation of $f^{\prime \prime}(0)$ with $\phi$ for different types of nanoparticles when $\operatorname{Pr}=7$ and $\lambda=2$.

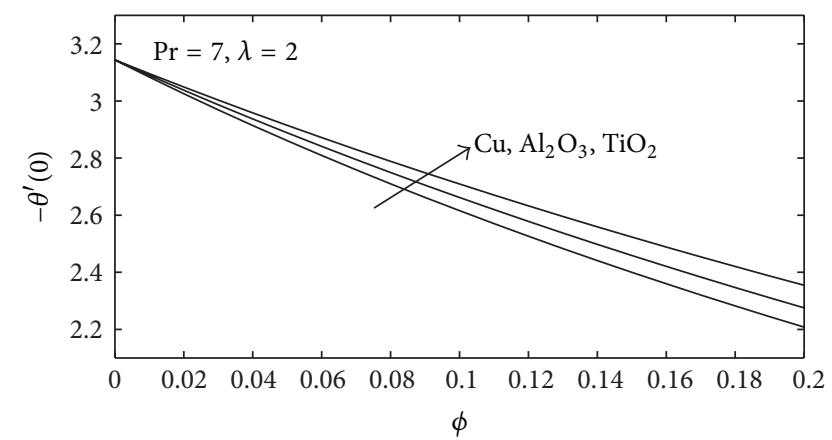

FIGURE 9: Variation of $-\theta^{\prime}(0)$ with $\phi$ for different types of nanoparticles when $\operatorname{Pr}=7$ and $\lambda=2$.

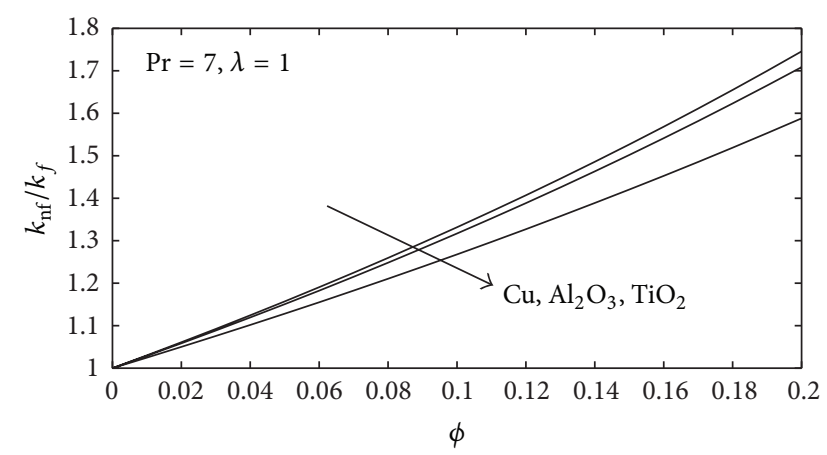

FIGURE 10: Variation of thermal conductivity ratio with $\phi$ for different types of nanoparticles when $\operatorname{Pr}=7$ and $\lambda=1$. compared to $\mathrm{Al}_{2} \mathrm{O}_{3}$-water and $\mathrm{Cu}$-water nanofluids. For a particular nanoparticle, increasing nanoparticle fraction is to reduce the skin friction coefficient and the heat transfer rate at the surface.

\section{Acknowledgments}

The financial supports received from the Ministry of Higher Education, Malaysia (Project code: FRGS/1/2012/ SG04/UKM/01/1), and the Universiti Kebangsaan Malaysia (Project code: DIP-2012-31) are gratefully acknowledged.

\section{References}

[1] Y. Ding, H. Chen, Y. He et al., "Forced convective heat transfer of nanofluids," Advanced Powder Technology, vol. 18, no. 6, pp. 813-824, 2007.

[2] X. Wang and A. S. Mujumdar, "Heat transfer characteristics of nanofluids: a review," International Journal of Thermal Sciences, vol. 46, no. 1, pp. 1-19, 2007.

[3] S. U. S. Choi, "Enhancing thermal conductivity of fluids with nanoparticles," in Proceedings of the International Mechanical Engineering Congress and Exposition, vol. 66, pp. 99-105, ASME, FED 231/MD, San Francisco, Calif, USA, 1995.

[4] H. Akoh, Y. Tsukasaki, S. Yatsuya, and A. Tasaki, "Magnetic properties of ferromagnetic ultrafine particles prepared by vacuum evaporation on running oil substrate," Journal of Crystal Growth, vol. 45, pp. 495-500, 1978.

[5] J. A. Eastman, U. S. Choi, S. Li, L. J. Thompson, and S. Lee, "Enhanced thermal conductivity through the development of nanofluids," in Proceedings of the Materials Research Society Symposium (MRS '96), vol. 457, pp. 3-11, Materials Research Society, Pittsburgh, Pa, USA, December 1996.

[6] E. Abu-Nada and H. F. Oztop, "Effects of inclination angle on natural convection in enclosures filled with $\mathrm{Cu}$-water nanofluid," International Journal of Heat and Fluid Flow, vol. 30, no. 4, pp. 669-678, 2009.

[7] K. Khanafer, K. Vafai, and M. Lightstone, "Buoyancy-driven heat transfer enhancement in a two-dimensional enclosure utilizing nanofluids," International Journal of Heat and Mass Transfer, vol. 46, no. 19, pp. 3639-3653, 2003.

[8] R. K. Tiwari and M. K. Das, "Heat transfer augmentation in a two-sided lid-driven differentially heated square cavity utilizing nanofluids," International Journal of Heat and Mass Transfer, vol. 50, no. 9-10, pp. 2002-2018, 2007.

[9] S. El Bécaye Maïga, S. J. Palm, C. T. Nguyen, G. Roy, and N. Galanis, "Heat transfer enhancement by using nanofluids in forced convection flows," International Journal of Heat and Fluid Flow, vol. 26, no. 4, pp. 530-546, 2005.

[10] G. Polidori, S. Fohanno, and C. T. Nguyen, "A note on heat transfer modelling of Newtonian nanofluids in laminar free convection," International Journal of Thermal Sciences, vol. 46, no. 8, pp. 739-744, 2007.

[11] F. Talebi, A. H. Mahmoudi, and M. Shahi, "Numerical study of mixed convection flows in a square lid-driven cavity utilizing nanofluid," International Communications in Heat and Mass Transfer, vol. 37, no. 1, pp. 79-90, 2010.

[12] M. Akbari, A. Behzadmehr, and F. Shahraki, "Fully developed mixed convection in horizontal and inclined tubes with uniform heat flux using nanofluid," International Journal of Heat and Fluid Flow, vol. 29, no. 2, pp. 545-556, 2008. 
[13] M. Shahi, A. H. Mahmoudi, and F. Talebi, "Numerical study of mixed convective cooling in a square cavity ventilated and partially heated from the below utilizing nanofluid," International Communications in Heat and Mass Transfer, vol. 37, no. 2, pp. 201-213, 2010.

[14] S. K. Das, S. U. S. Choi, W. Yu, and T. Pradeep, Nanofluids: Science and Technology, Wiley, Hoboken, NJ, USA, 2007.

[15] S. Kakaç and A. Pramuanjaroenkij, "Review of convective heat transfer enhancement with nanofluids," International Journal of Heat and Mass Transfer, vol. 52, no. 13-14, pp. 3187-3196, 2009.

[16] E. Abu-Nada, "Application of nanofluids for heat transfer enhancement of separated flows encountered in a backward facing step," International Journal of Heat and Fluid Flow, vol. 29, no. 1, pp. 242-249, 2008.

[17] S. Ahmad, A. M. Rohni, and I. Pop, "Blasius and Sakiadis problems in nanofluids," Acta Mechanica, vol. 218, no. 3-4, pp. 195-204, 2011.

[18] A. M. Rohni, S. Ahmad, and I. Pop, "Boundary layer flow over a moving surface in a nanofluid beneath a uniform free stream," International Journal of Numerical Methods for Heat and Fluid Flow, vol. 21, no. 7, pp. 828-846, 2011.

[19] N. Bachok, A. Ishak, R. Nazar, and I. Pop, "Flow and heat transfer at a general three-dimensional stagnation point in a nanofluid," Physica B, vol. 405, no. 24, pp. 4914-4918, 2010.

[20] N. Bachok, A. Ishak, and I. Pop, "Flow and heat transfer over a rotating porous disk in a nanofluid," Physica B, vol. 406, no. 9, pp. 1767-1772, 2011.

[21] N. Bachok, A. Ishak, and I. Pop, "Stagnation-point flow over a stretching/shrinking sheet in a nanofluid," Nanoscale Research Letters, vol. 6, article 623, 2011.

[22] N. Bachok, A. Ishak, and I. Pop, "Flow and heat transfer characteristics on a moving plate in a nanofluid," International Journal of Heat and Mass Transfer, vol. 55, no. 4, pp. 642-648, 2012.

[23] N. Bachok, A. Ishak, and I. Pop, "Boundary layer flow over a moving surface in a nanofluid with suction or injection," Acta Mechanica Sinica, vol. 28, no. 1, pp. 34-40, 2012.

[24] N. A. Yacob, A. Ishak, I. Pop, and K. Vajravelu, "Boundary layer flow past a stretching/shrinking surface beneath an external uniform shear flow with a convective surface boundary condition in a nanofluid," Nanoscale Research Letters, vol. 6, article 314, 2011.

[25] N. A. Yacob, A. Ishak, and I. Pop, "Falkner-Skan problem for a static or moving wedge in nanofluids," International Journal of Thermal Sciences, vol. 50, no. 2, pp. 133-139, 2011.

[26] M. Muthtamilselvan, P. Kandaswamy, and J. Lee, "Heat transfer enhancement of copper-water nanofluids in a lid-driven enclosure," Communications in Nonlinear Science and Numerical Simulation, vol. 15, no. 6, pp. 1501-1510, 2010.

[27] D. A. Nield and A. V. Kuznetsov, "The Cheng-Minkowycz problem for natural convective boundary-layer flow in a porous medium saturated by a nanofluid," International Journal of Heat and Mass Transfer, vol. 52, no. 25-26, pp. 5792-5795, 2009.

[28] A. V. Kuznetsov and D. A. Nield, "Natural convective boundarylayer flow of a nanofluid past a vertical plate," International Journal of Thermal Sciences, vol. 49, no. 2, pp. 243-247, 2010.

[29] H. F. Oztop and E. Abu-Nada, "Numerical study of natural convection in partially heated rectangular enclosures filled with nanofluids," International Journal of Heat and Fluid Flow, vol. 29, no. 5, pp. 1326-1336, 2008.
[30] L. J. Grubka and K. M. Bobba, "Heat transfer charateristics of a continuous, stretching surface with variable temperature," Journal of Heat Transfer, vol. 107, no. 1, pp. 248-250, 1985.

[31] A. Ishak, R. Nazar, and I. Pop, "Unsteady mixed convection boundary layer flow due to a stretching vertical surface," Arabian Journal for Science and Engineering, vol. 31, no. 2 B, pp. 165-182, 2006.

[32] T. Cebeci and P. Bradshaw, Physical and Computational Aspects of Convective Heat Transfer, Springer, New York, NY, USA, 1988. 


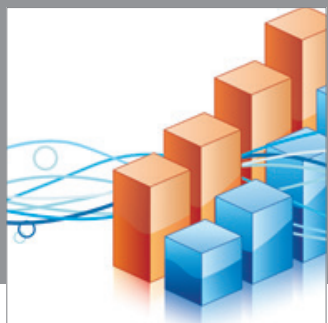

Advances in

Operations Research

mansans

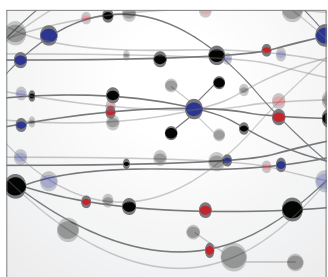

The Scientific World Journal
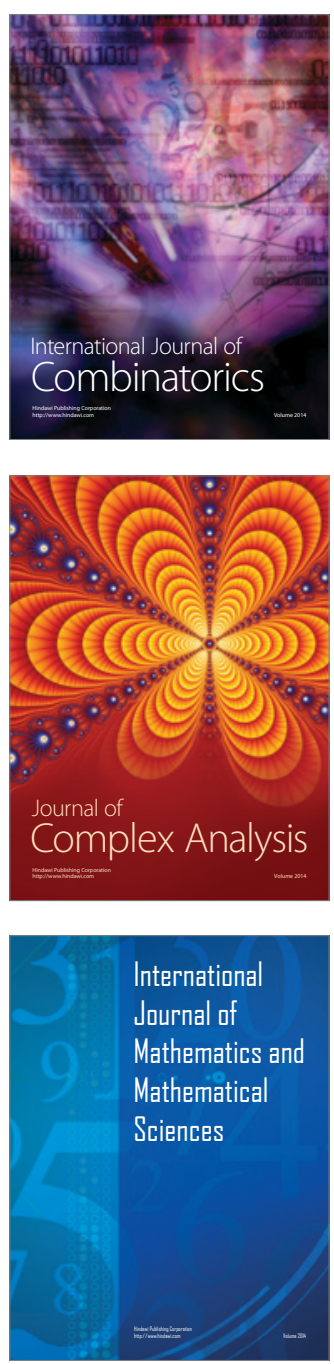
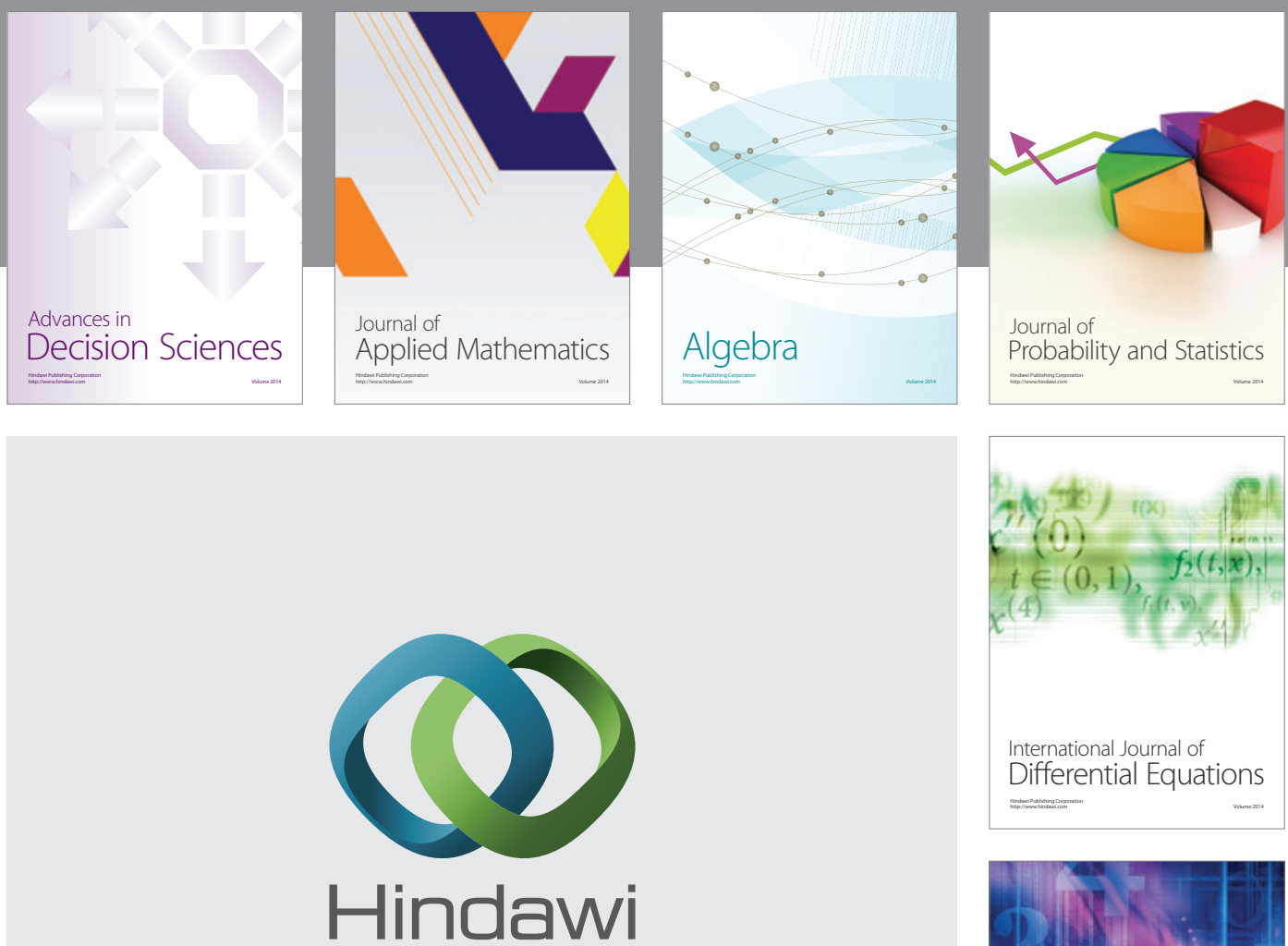

Submit your manuscripts at http://www.hindawi.com
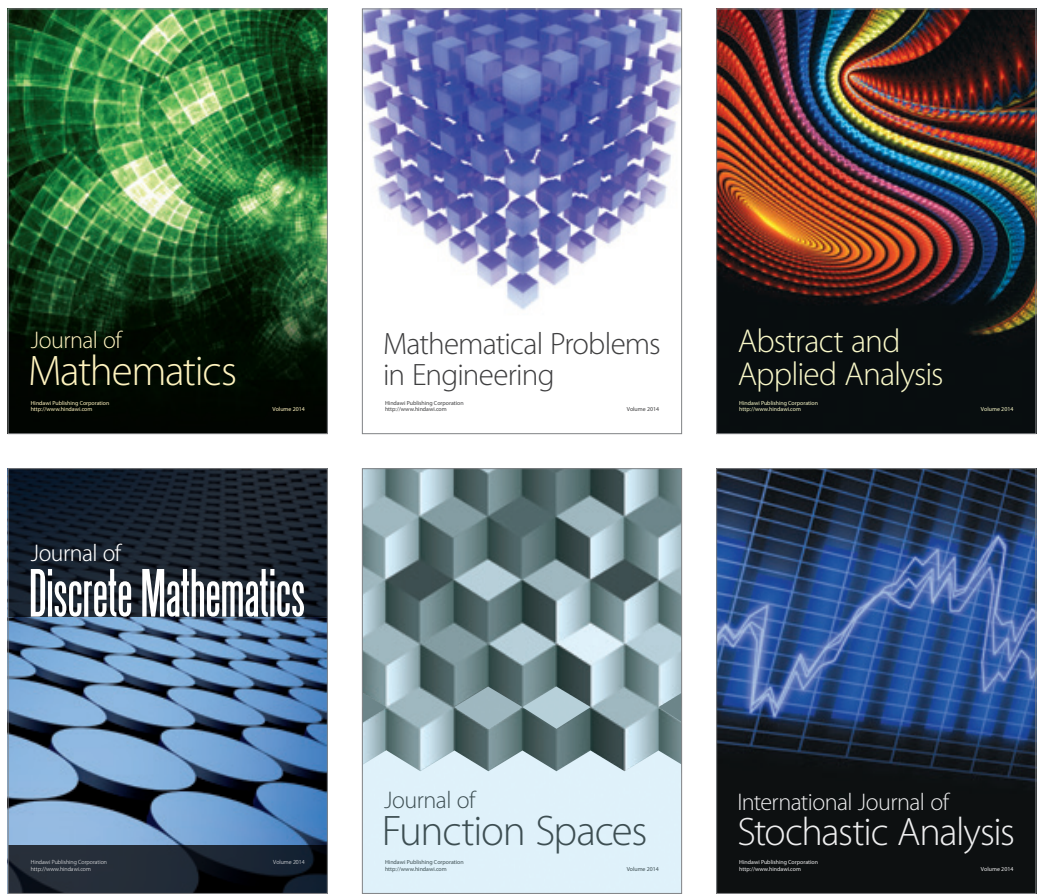

Journal of

Function Spaces

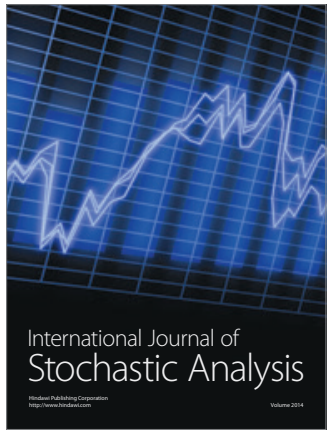

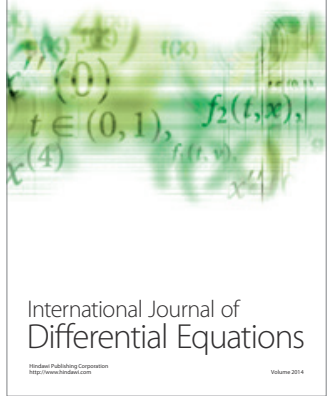
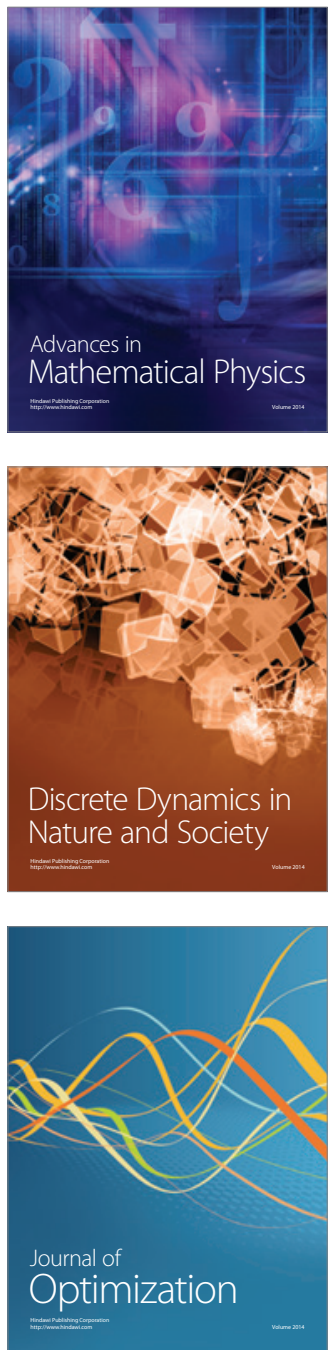